\title{
Utilization of intravenous bisphosphonates in patients with bone metastases secondary to breast, lung, or prostate cancer
}

\author{
May Hagiwara $\cdot$ Thomas E. Delea $\cdot$ Ze Cong $\cdot$ Karen Chung
}

Received: 29 March 2013 / Accepted: 21 August 2013 /Published online: 3 September 2013

(C) Springer-Verlag Berlin Heidelberg 2013

\begin{abstract}
Purpose Cancer patients with bone metastases (BMets) are predisposed to skeletal complications. Bone-targeted therapies such as denosumab or intravenous bisphosphonates (IVBs) reduce the risk of these complications. This study characterized patterns of IVB use in these patients in the USA.

Methods This was a retrospective, observational study using the Truven Health MarketScan ${ }^{\circledR}$ Commercial and Medicare databases (2002-2011). Subjects with $\geq 1$ claims of diagnosis of breast, lung, or prostate cancer (BC, LC, or PC) and $\geq 1$ claims of BMets diagnosis were included. The date of first BMet diagnosis claim was the "index date." Key exclusion criteria were diagnosis of other primary cancer, receipt of IVB, or $<6$ months continuous enrollment pre-index. Cumulative incidence of treatment initiation, interruption, and discontinuation were estimated. Proportions of IVB claims with chemotherapy administered on the same day and with renal monitoring within 2 weeks prior were summarized. Multivariate regressions assessing factors associated with IVB initiation were conducted.

Results Cumulative incidence of IVB initiation at 12 months post-index was greatest for $\mathrm{BC}$ followed by $\mathrm{PC}$ and $\mathrm{LC}$, and it declined with age in all tumor types, e.g., in BC from $62 \%$ at age $<50$ years to $47 \%$ at age $\geq 75$ years. At 12 months, IVB
\end{abstract}

M. Hagiwara $(\bowtie) \cdot$ T. E. Delea

Policy Analysis Inc. (PAI), Four Davis Court, Brookline,

MA 02445, USA

e-mail: mhagiwara@pai2.com

Z. Cong $\cdot$ K. Chung

Global Health Economics, Amgen Inc., One Amgen Center Drive,

Thousand Oaks, CA, USA treatment interruption ranged from $16 \%(\mathrm{LC})$ to $31 \%(\mathrm{PC})$, with discontinuation ranging from $46 \%$ (BC) to $83 \%$ (LC). Conclusions IVBs are used more frequently in patients with BMets secondary to BC than PC or LC. Many patients interrupt or discontinue IVB therapy within 12 months of initiation potentially impacting effectiveness.

Keywords Intravenous bisphosphonates $\cdot$ Solid tumor $\cdot$ Bone metastases $\cdot$ Healthcare utilization

\section{Introduction}

Bone is the most common site of metastases of many solid tumors. Patients with bone metastases of solid tumors are at risk of a variety of skeletal complications including spinal cord compression, pathological fracture, bone surgery, and radiotherapy to bone. These complications are collectively referred to as skeletal-related events (SREs) [1]. Bone metastases and SREs predict short survival in patients with breast and prostate cancer [2,3]. Intravenous bisphosphonates (IVBs) such as zoledronic acid and pamidronate have been shown to prevent the occurrence of SREs in patients with bone metastases secondary to solid tumors [4-7]. Prior to the approval of denosumab in the USA in 2010, the IVBs have been the prevailing treatment for the prevention of SREs among patients with solid tumors and bone metastases. However, information on IVB utilization patterns among patients with solid tumors and bone metastases is not available. This information may be useful to identify potential gaps in treatment that may be addressed to improve patient outcomes. The objective of this study was to document IVB practice patterns in patients with bone metastases of breast, lung, or prostate cancer using the latest data 
available from the Truven Health MarketScan ${ }^{\circledR}$ Commercial and Medicare databases.

\section{Materials and methods}

Study design and data source

This study was a retrospective analysis of administrative claims data from Truven Health MarketScan ${ }^{\circledR}$ Commercial Claims and Encounters and Medicare and Coordination of Benefits Databases from September 1, 2002 through June 30, 2011 ("study period"). These databases contain information on health insurance claims of employees of large, self-insured corporations and their dependents, along with a few commercial health plans, and of Medicare eligible persons who are also covered by self-insured employers. Both databases are fully deidentified and compliant with the Health Insurance Portability and Accountability Act of 1996. Accordingly, institutional review board approval was not necessary.

\section{Patient selection}

Study subjects included all persons who had evidence of breast, lung, or prostate cancer and evidence of bone metastases. Breast, lung, and prostate cancers were identified based on either one or more inpatient facility claims with a primary discharge diagnosis of female breast cancer (International Classification of Diseases Version 9 Clinical Modification [ICD-9-CM] 174.xx), lung cancer (ICD-9-CM 162.xx), or prostate cancer (ICD-9-CM 185.xx) or two or more claims on different days not more than 6 months apart with a diagnosis of breast, lung, or prostate cancer. Bone metastases were identified by one or more inpatient facility claims with a primary discharge diagnosis of bone metastases (ICD-9-CM 170.xx or 198.5x) or two or more outpatient claims on different days not more than 6 months apart with a diagnosis of bone metastases during the study period. The date of claims was the service date for outpatient claims, while for inpatient claims, it was the admission date. For each patient, the "index date" was defined as the date of the first claim with a diagnosis of bone metastases. The 6-month period prior to the index date was designated the "pre-index period"; the period from the index date to the end of continuous enrollment was designated the "follow-up period." Exclusion criteria were as follows: age less than 18 years as of the index date, male patients with diagnosis of breast cancer or female patients with diagnosis of prostate cancer, less than 6 months of continuous enrollment prior to index date, less than 1 month (30 days) of continuous enrollment on or after index date, no use of IVBs prior to index date, no diagnosis for qualifying primary cancer on or prior to the index date, and diagnosis of primary cancer other than the qualifying primary cancer (i.e., breast, lung, or prostate cancer) prior to the index date. The algorithm and specific codes for identification of primary and secondary malignancies by site are listed in the Appendix.

Patients meeting the inclusion/exclusion criteria were classified into three mutually exclusive groups defined by tumor type (breast, lung, or prostate cancer).

\section{Patient characteristics}

For each patient, baseline demographic characteristics were assessed as of the index date, including calendar year, age, gender, region, and plan type. Comorbidities were assessed based on Deyo's version of the Charlson Comorbidity Index [8]. Also, claims during the 6-month pre-index period were

Table 1 Selection of study subjects by tumor type

\begin{tabular}{llll}
\hline Criteria & $\begin{array}{l}\text { Breast cancer with bone } \\
\text { metastasis, } n(\%)\end{array}$ & $\begin{array}{l}\text { Lung cancer with bone } \\
\text { metastasis, } n(\%)\end{array}$ & $\begin{array}{l}\text { Prostate cancer with bone } \\
\text { metastasis, } n(\%)\end{array}$ \\
\hline $\begin{array}{l}\text { Diagnosis of solid tumor prior to bone metastases diagnosis } \\
\text { Exclusions }\end{array}$ & $23,909(100)$ & $20,609(100)$ & $14,293(100)$ \\
Age less than 18 years on index date & $74(0.3)$ & $51(0.2)$ & $21(0.1)$ \\
Breast cancer patients who are male & $91(0.4)$ & $\mathrm{NA}$ & $\mathrm{NA}$ \\
Prostate cancer patients who are female & $\mathrm{NA}$ & $\mathrm{NA}$ & $54(0.4)$ \\
Less than 6 months of continuous enrollment prior to index date & $7,700(32.2)$ & $4,655(22.6)$ & $3,576(25.0)$ \\
Less than 30 days of continuous enrollment during follow-up & $711(3.0)$ & $1,281(6.2)$ & $370(2.6)$ \\
Received IVBs prior to index date & $4,429(18.5)$ & $1,485(7.2)$ & $1,766(12.4)$ \\
More than one type of primary cancer prior to index date & $1,767(7.4)$ & $3,860(18.7)$ & $1,845(12.9)$ \\
Missing information & $700(2.9)$ & $358(1.7)$ & $451(3.2)$ \\
Total excluded & $12,239(51.2)$ & $9,627(46.7)$ & $6,697(46.9)$ \\
Remaining & $11,670(48.8)$ & $10,982(53.3)$ & $7,596(53.1)$
\end{tabular}

$I V B$ intravenous bisphosphonate 
Table 2 Patient characteristics at baseline by tumor type

\begin{tabular}{|c|c|c|c|}
\hline Characteristic & $\begin{array}{l}\text { Breast cancer with bone } \\
\text { metastasis }(n=11,670)\end{array}$ & $\begin{array}{l}\text { Lung cancer with bone } \\
\text { metastasis }(n=10,982)\end{array}$ & $\begin{array}{l}\text { Prostate cancer with bone } \\
\text { metastasis }(n=7,596)\end{array}$ \\
\hline \multicolumn{4}{|l|}{ Index year, $n(\%)$} \\
\hline 2003 & $633(5.4)$ & $603(5.5)$ & $502(6.6)$ \\
\hline 2004 & $887(7.6)$ & $905(8.2)$ & $741(9.8)$ \\
\hline 2005 & $1,078(9.2)$ & $1,069(9.7)$ & $835(11.0)$ \\
\hline 2006 & $1,198(10.3)$ & $1,055(9.6)$ & $688(9.1)$ \\
\hline 2007 & $1,476(12.6)$ & $1,310(11.9)$ & $851(11.2)$ \\
\hline 2008 & $1,750(15.0)$ & $1,683(15.3)$ & $1,087(14.3)$ \\
\hline 2009 & $2,331(20.0)$ & $2,108(19.2)$ & $1,331(17.5)$ \\
\hline 2010 & $1,718(14.7)$ & $1,638(14.9)$ & $1,157(15.2)$ \\
\hline 2011 (Through June 30) & $599(5.1)$ & $611(5.6)$ & $404(5.3)$ \\
\hline Age, year, mean (SD) & $59.4(12.7)$ & $64.3(10.8)$ & $73.4(10.7)$ \\
\hline Males, $n(\%)$ & NA & $6,027(54.9)$ & $7,596(100.0)$ \\
\hline \multicolumn{4}{|l|}{ Region, $n(\%)$} \\
\hline South & $4,504(38.6)$ & $3,850(35.1)$ & $2,221(29.2)$ \\
\hline North Central & $3,308(28.3)$ & $3,617(32.9)$ & $2,447(32.2)$ \\
\hline West & 2,087 (17.9) & $1,653(15.1)$ & $1,674(22.0)$ \\
\hline Northeast & $1,515(13.0)$ & $1,561(14.2)$ & $1,088(14.3)$ \\
\hline Unknown & $256(2.2)$ & $301(2.7)$ & $166(2.2)$ \\
\hline \multicolumn{4}{|l|}{ Plan type, $n(\%)$} \\
\hline PPO & $6,305(54.0)$ & $5,463(49.7)$ & $2,864(37.7)$ \\
\hline Comprehensive & 2,049 (17.6) & $2,795(25.5)$ & $2,983(39.3)$ \\
\hline $\mathrm{HMO}$ & $1,717(14.7)$ & $1,474(13.4)$ & $1,157(15.2)$ \\
\hline Other & $1,599(13.7)$ & $1,250(11.4)$ & $592(7.8)$ \\
\hline Charlson index, mean $(\mathrm{SD})^{\mathrm{a}}$ & $4.6(3.2)$ & $5.6(3.4)$ & $3.4(2.5)$ \\
\hline \multicolumn{4}{|c|}{ Additional sites of metastases during pre-index period, $n(\%)$} \\
\hline Lymph nodes & $1,641(14.1)$ & $1,259(11.5)$ & $251(3.3)$ \\
\hline Respiratory sites & $1,466(12.6)$ & $9,873(89.9)$ & $183(2.4)$ \\
\hline Liver & $1,004(8.6)$ & $1,111(10.1)$ & $78(1.0)$ \\
\hline Central nervous system & $740(6.3)$ & $1,778(16.2)$ & $78(1.0)$ \\
\hline Other sites & $1,437(12.3)$ & $982(8.9)$ & $460(6.1)$ \\
\hline None & $7,300(62.6)$ & $1,075(9.8)$ & $6,704(88.3)$ \\
\hline \multicolumn{4}{|l|}{ Visits to specialist during pre-index period, $n(\%)$} \\
\hline Oncologist & $4,155(35.6)$ & $3,392(30.9)$ & $1,258(16.6)$ \\
\hline Urologist & NA & NA & $4,406(58.0)$ \\
\hline \multicolumn{4}{|l|}{ Healthcare utilization during pre-index period } \\
\hline Number of physician office visits, mean (SD) & $12(10.4)$ & $15(12.3)$ & $10(8.2)$ \\
\hline Number of hospital outpatient visits, mean (SD) & $6(7.8)$ & $9(9.7)$ & $4(5.8)$ \\
\hline Hospitalization, $n(\%)$ & $2,105(18.0)$ & $3,808(34.7)$ & $1,242(16.4)$ \\
\hline Oral bisphosphonate, $n(\%)$ & $990(8.5)$ & $436(4.0)$ & $328(4.3)$ \\
\hline Long-acting opioid, $n(\%)$ & $978(8.4)$ & $2,357(21.5)$ & $512(6.7)$ \\
\hline Short-acting opioid, $n(\%)$ & $5,859(50.2)$ & $7,102(64.7)$ & $3,259(42.9)$ \\
\hline Chemotherapy, $n(\%)$ & $3,552(30.4)$ & $4,328(39.4)$ & $3,452(45.4)$ \\
\hline Systemic corticosteroid, $n(\%)$ & $3,955(33.9)$ & $6,333(57.7)$ & $1,931(25.4)$ \\
\hline Targeted therapy, $n(\%)$ & $927(7.9)$ & $932(8.5)$ & $17(0.2)$ \\
\hline Hormonal therapy during pre-index period, $n(\%)$ & $3,915(33.5)$ & $473(4.3)$ & $4,689(61.7)$ \\
\hline Hypercalcemia & $62(0.5)$ & $45(0.4)$ & $16(0.2)$ \\
\hline \multicolumn{4}{|l|}{ SREs during pre-index period, $n(\%)$} \\
\hline Radiotherapy & $98(0.8)$ & $159(1.4)$ & $26(0.3)$ \\
\hline
\end{tabular}


Table 2 (continued)

\begin{tabular}{llll}
\hline Characteristic & $\begin{array}{l}\text { Breast cancer with bone } \\
\text { metastasis }(n=11,670)\end{array}$ & $\begin{array}{l}\text { Lung cancer with bone } \\
\text { metastasis }(n=10,982)\end{array}$ & $\begin{array}{l}\text { Prostate cancer with bone } \\
\text { metastasis }(n=7,596)\end{array}$ \\
\hline Pathological fracture & $567(4.9)$ & $492(4.5)$ & $246(3.2)$ \\
Surgery to bone & $78(0.7)$ & $112(1.0)$ & $31(0.4)$ \\
Spinal cord compression & $13(0.1)$ & $22(0.2)$ & $3(0.0)$ \\
Duration of follow-up, months, mean (SD) & $16.5(15.4)$ & $7.7(8.3)$ & $15.5(14.4)$ \\
\hline
\end{tabular}

SRE skeletal-related event; $S D$ standard deviation; $P P O$ preferred provider organization; $H M O$ health maintenance organization

${ }^{a}$ Calculated over 6 months prior to index date

assessed for presence of diagnoses of additional sites of metastases (lymph nodes, respiratory sites, liver, central nervous system, and other sites), evidence of visits to specialist (hematologist, oncologist, and urologist [for prostate cancer patients]), hospitalizations, receipts of medications/services for oral bisphosphonates, long-acting and short-acting opioids, chemotherapy, systemic corticosteroids, targeted therapy, hormonal therapy, orchiectomy (for prostate cancer patients), SREs, hypercalcemia, and number of physicians' office visits and hospital outpatient visits. SREs were identified using algorithms employed in a previously published study [9].

\section{Outcome measures and analyses}

The primary measure of interest was the time from index date (bone metastases diagnosis) to the first claim for IVB therapy during follow-up period. Time to first IVB therapy claim was analyzed by tumor type using cumulative incidence methods with death as a competing risk $[10,11]$. Because information on mortality was unavailable, the date of disenrollment from a plan was used as a proxy for death as mortality. Because patients with metastatic cancer are not likely to otherwise disenroll from their health plans, disenrollment is likely a reasonable proxy for mortality $[12,13]$. Patients who did not receive any IVBs during the study period and were enrolled at the end of the study period were censored.

For patients who received IVBs during follow-up, time to IVB therapy interruption and IVB therapy discontinuation were analyzed. Interruption was defined as the time from IVB therapy initiation to the first occurrence of gap of more than 60 days without a subsequent IVB claim as IVB administration is recommended every 3 to 4 weeks. Time to IVB therapy discontinuation was defined as the time from therapy initiation to the date of last IVB claim. Time to interruption and discontinuation were analyzed by tumor type using cumulative incidence methods. For analyses of time to treatment interruption, therapy discontinuation was defined as a competing risk. For analyses of time to discontinuation, patients with a last claim for IVB within 60 days of the end of the study were censored.

Among patients who received IVBs during the follow-up period, each IVB administration was assessed for evidence of concurrent chemotherapy (IV, oral, or other chemotherapy) on the same day and for evidence of renal function tests on or within a 14-day period before the IVB administration. The number and percentage of IVB administrations with concurrent chemotherapy or renal function tests were calculated by tumor type.

The associations between various independent variables and receipt of IVBs during follow-up were analyzed and expressed as hazard ratios with $95 \%$ confidence intervals. Stepwise longitudinal Cox proportional hazards regression analyses were conducted by tumor type where patient characteristics and time-dependent covariates were selected for entry into the model based on a $P$ value $\leq 0.20$ and dropped from the model based on a $P$ value $\geq 0.10$. Time-dependent variables for SREs (spinal cord compression, pathological fracture, surgery to bone, and radiotherapy to bone) and hypercalcemia of malignancy were forced into these models. Other timedependent covariates included receipt of long-acting and short-acting opioids, systemic corticosteroids, chemotherapy, targeted therapy (i.e., bevacizumab, crizotinib, erlotinib, gefitinib, lapatinib, and trastuzumab), hormonal therapy, and orchiectomy procedure. All patient characteristics assessed on index date and over the pre-index period were also included.

All analyses were conducted using SAS ${ }^{\circledR}$ Proprietary Software, Release 9.2.3 (SAS Institute Inc., Cary, NC).

\section{Results}

Among 23,909 patients with bone metastases and breast cancer identified in the databases, 11,670 patients (49\%) qualified for the study. Among 20,609 patients with bone metastases and lung cancer, 10,982 patients (53\%) qualified for the study. Among 14,293 patients with bone metastases and prostate cancer, 7,596 patients (53\%) qualified for the study (Table 1). 
Fig. 1 Cumulative incidence of IVB therapy initiation and IVB therapy interruption and discontinuation by tumor type: a IVB therapy initiation since index date (first IVB claim, death as competing risk), b IVB therapy interruption (gap of $>60$ days between IVB claims, discontinuation as competing risk), c IVB therapy discontinuation (last IVB claim). Footnote numbers reported under each figure are number of patients at risk at month $0,12,24$, and 36 reported by tumor type a. IVB therapy initiation since index date (first IVB claim, death as competing risk)

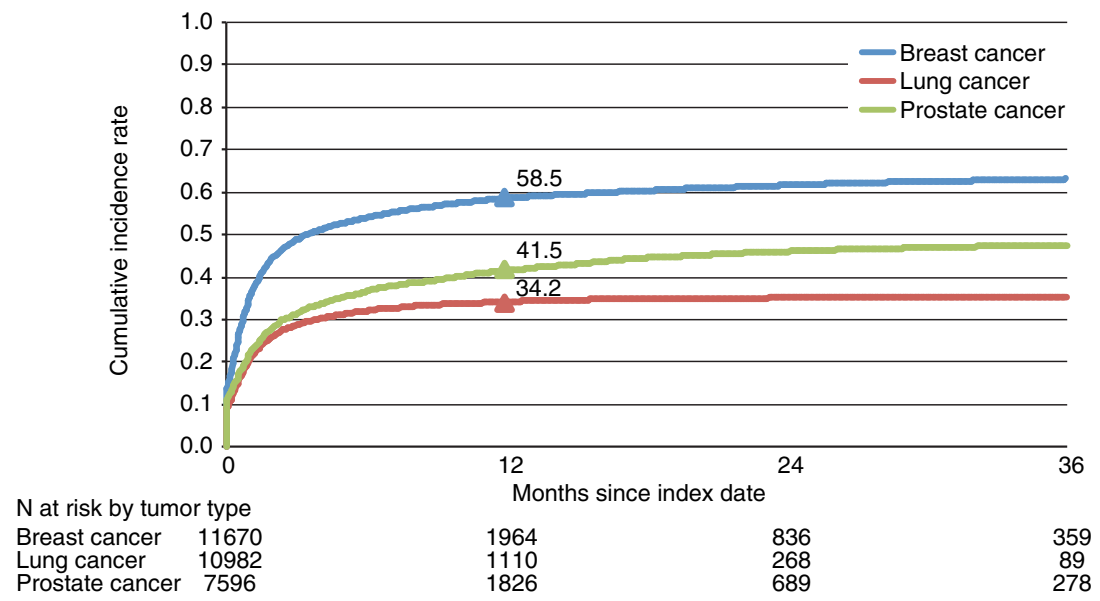

b. IVB therapy interruption (gap of $>60$ days between IVB claims, discontinuation as competing risk)

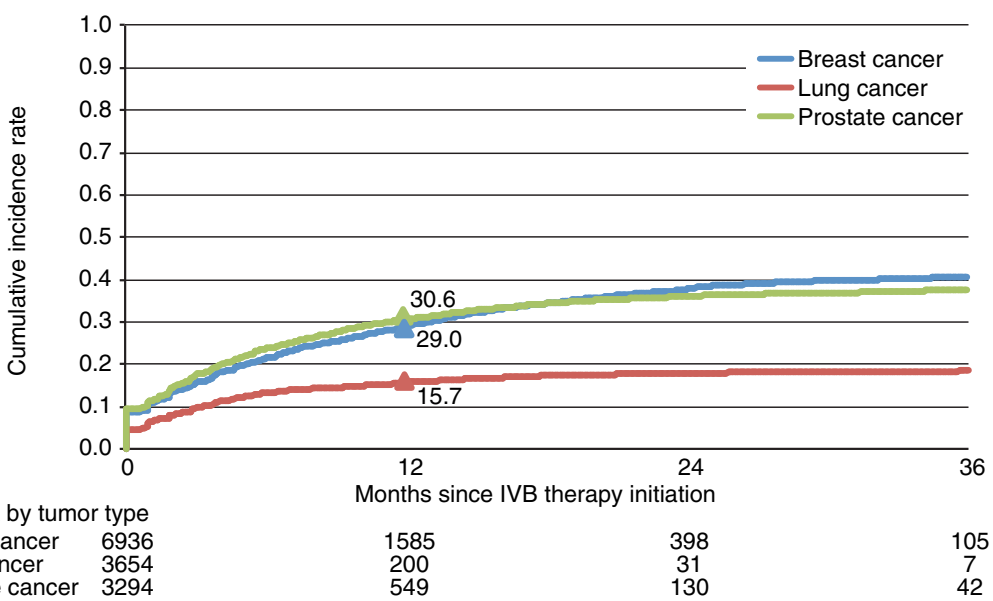

C. IVB therapy discontinuation (last IVB claim)

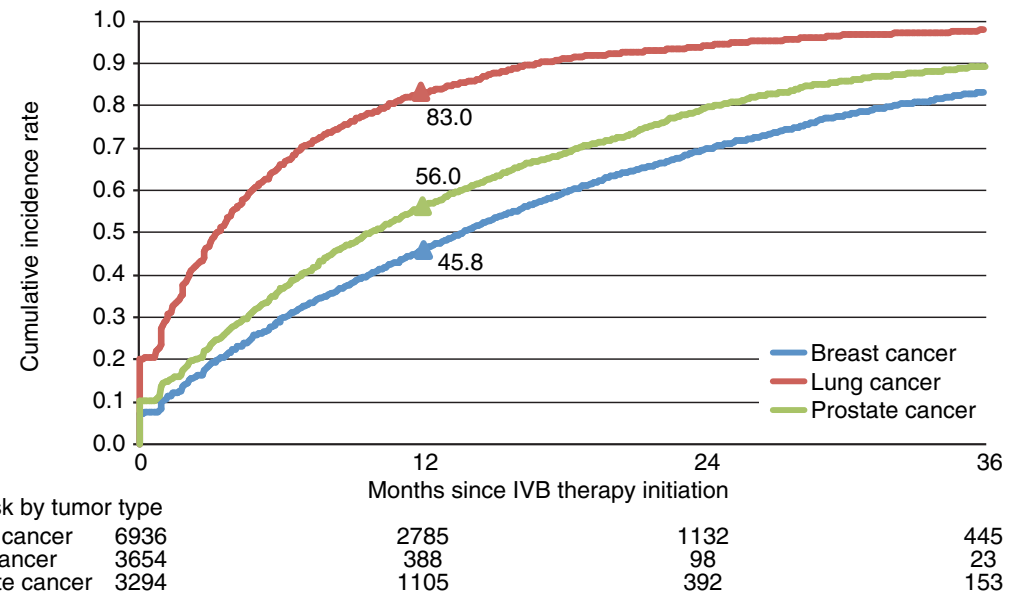

The most frequent reason for exclusion was $<6$ months of continuous enrollment prior to the index date.

Mean (SD) age was 59.4 (12.7)years, 64.3 (10.8) years, and 73.4 (10.7)years in the breast, lung, and prostate cancer cohort, respectively (Table 2). In the lung cancer cohort, $55 \%$ were male. For all cohorts, the majority of patients resided in the South or the North Central regions and were enrolled in preferred provider 
Fig. 2 Cumulative incidence of IVB therapy initiation by index age with death as competing risk: a breast cancer with bone metastasis, b lung cancer with bone metastasis, c. prostate cancer with bone metastasis a. Breast cancer with bone metastasis

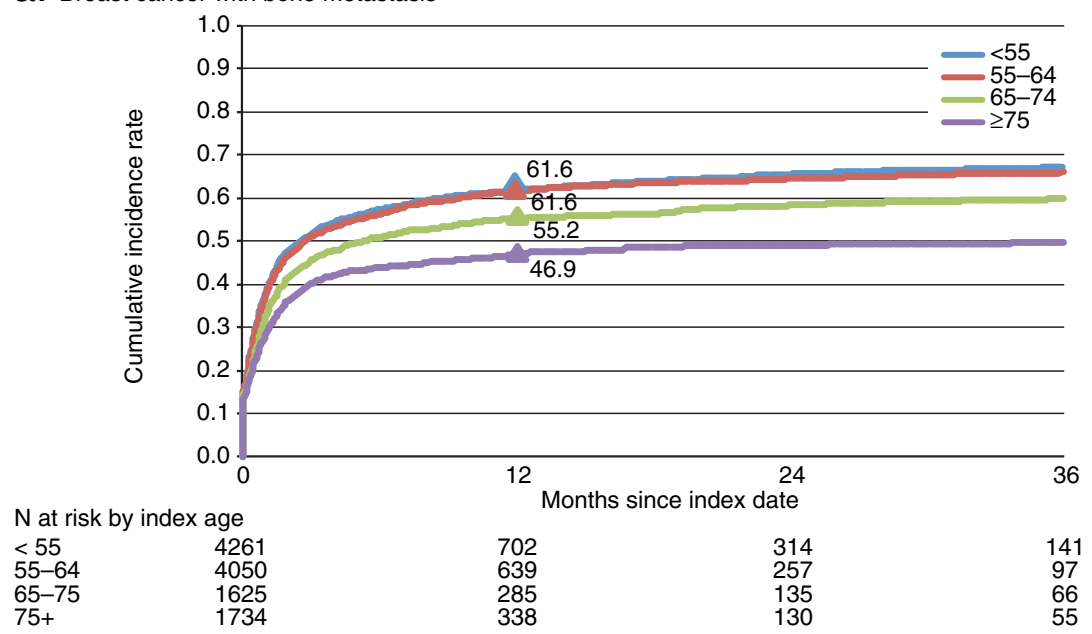

b. Lung cancer with bone metastasis

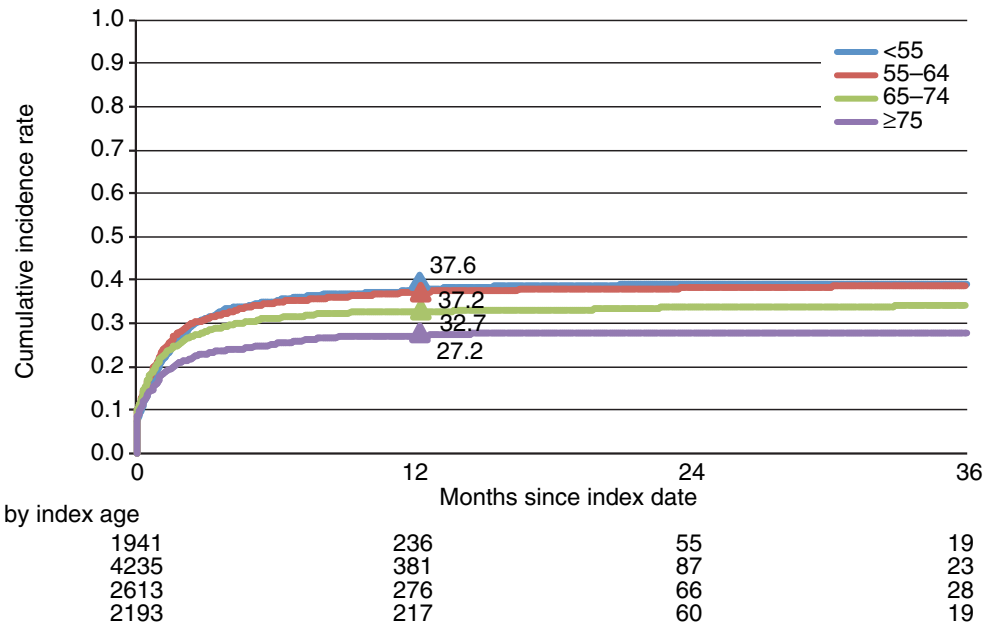

C. Prostate cancer with bone metastasis

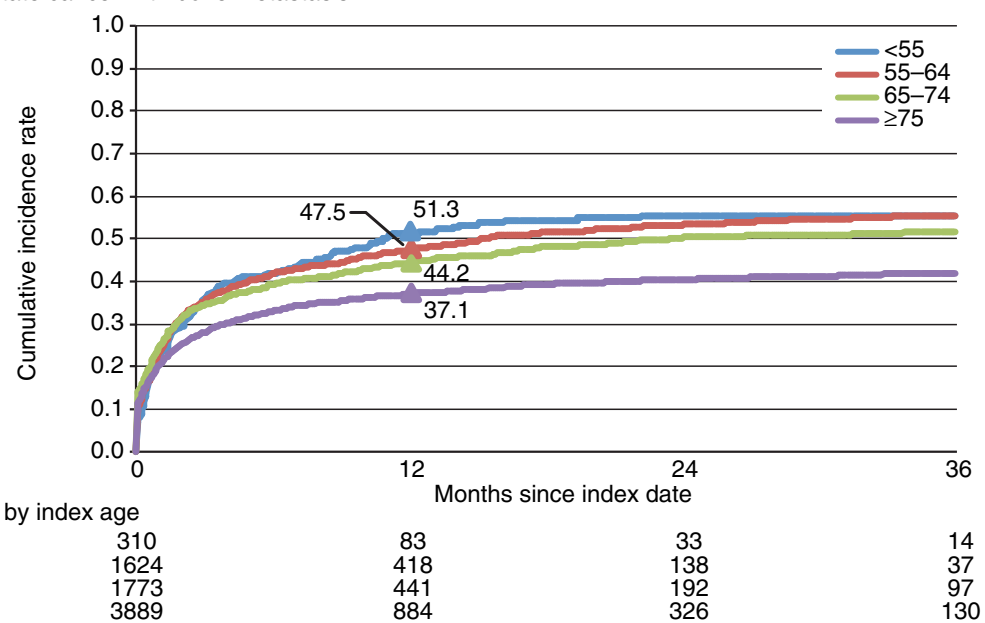

organizations (PPOs) or comprehensive plans. Based on the mean (SD) Charlson index during the pre-index period, lung cancer patients had the most comorbidities, followed by breast and prostate cancer patients. The mean (SD) duration of follow-up was 16.5 (15.4)months,
7.7 (8.3)months, and 15.5 (14.4)months among the breast, lung, and prostate cancer cohorts, respectively.

During the follow-up period, among the three tumor types, breast cancer patients received IVBs most frequently $(n=$ 6,$936 ; 59 \%$ ), followed by prostate cancer patients ( $n=3,294$; 
$43 \%)$ and lung cancer patients $(n=3,654 ; 33 \%)$. Cumulative incidence of IVB initiation 12 months post-index was greatest among breast cancer patients, $58.5 \%$ (95\% confidence interval [CI] 57.6 to $59.4 \%$ ), followed by prostate cancer patients, $41.5 \%$ (95\% CI 40.4 to $42.7 \%$ ), and lung cancer patients, $34.2 \%$ (95\% CI 33.3 to $35.2 \%$ ) (Fig. 1). IVB treatment interruption at 12 months after IVB initiation was greatest among prostate cancer patients $(30.6 \%, 95 \%$ CI 28.9 to $32.2 \%)$, followed by breast cancer patients $(29.0 \%, 95 \%$ CI 27.9 to $30.3 \%$ ), and lung cancer patients (15.7\%, $95 \%$ CI 14.5 to $17.0 \%$ ). IVB treatment discontinuation after IVB initiation at 12 months was greatest among lung cancer patients $(83.0 \%$, $95 \%$ CI 81.6 to $84.3 \%$ ), followed by prostate cancer patients (56.0\%, $95 \%$ CI 54.2 to $57.9 \%$ ), and breast cancer patients ( $45.8 \%, 95 \%$ CI 44.6 to $47.1 \%$ ). Cumulative incidence of IVB therapy initiation at 12 months after bone metastases diagnosis declined with age in all tumor types (Fig. 2), e.g., among breast cancer patients, cumulative incidence at 12 months ranged from $61.6 \%$ at age $<55$ years to $46.9 \%$ at age $\geq 75$ years.

There were 78,118 IVB claims identified during follow-up among 11,670 breast cancer patients with bone metastases. Similarly, 19,077 and 31,954 IVB claims were identified among 10,982 lung cancer patients with bone metastases and among 7,596 prostate cancer patients with bone metastases, respectively. Among breast cancer patients, IV chemotherapy was administered on the same day as IVB for $38 \%$ of IVB claims (Table 3). The corresponding values for lung and prostate cancer patients were 54 and $26 \%$ respectively. Renal monitoring was performed on the same day or within a 2week period before IVB administration for 65,61 , and $42 \%$ of IVB claims among breast, lung, and prostate cancer patients, respectively.

In the multivariable longitudinal proportional hazard regression analyses predicting receipt of IVBs (Table 4), evidence of SREs and hypercalcemia were associated with greater subsequent use of IVBs in general. Among breast cancer patients, hypercalcemia was associated with the greatest use of IVBs (HR $=1.86,95 \%$ CI 1.49 to 2.32 ), followed by radiotherapy ( $\mathrm{HR}=1.34,95 \% \mathrm{CI} 1.26$ to 1.43$)$, surgery to bone $(\mathrm{HR}=1.19,95 \% \mathrm{CI} 1.05$ to 1.35$)$, and pathological fracture $(\mathrm{HR}=1.14,95 \% \mathrm{CI} 1.03$ to 1.25$)$. Among lung and prostate cancer patients, estimated HRs for SREs and hypercalcemia were qualitatively similar. Spinal cord compression was associated with lower rates of IVB utilization in breast and lung cancer patients.

In lung and breast cancer patients, later calendar index year was generally associated with greater utilization of IVBs. The exception was index year of 2011, which was associated with lower utilization, although this finding was not statistically significant. Visits to hematologists were associated with greater use of IVBs in the breast and prostate cancer cohorts, and visits to oncologists were associated with greater use of IVBs

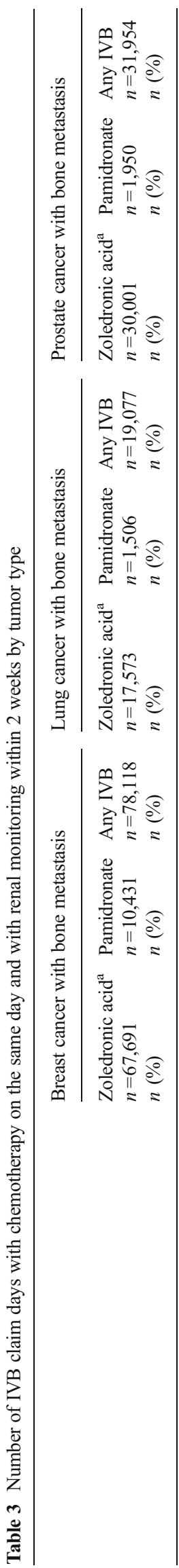

ఠิ $\odot$

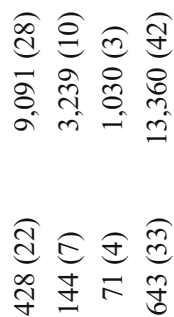

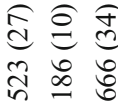

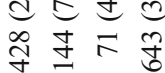

$\stackrel{\overbrace{}}{\ominus}$

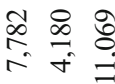

बृ월

तुㅇㅇㅇ है ?

点 $\overparen{d}$ 吉

तै

产 $气 \hat{\sigma}$

\begin{tabular}{llll}
8 & $\infty$ & 0 & $\infty$ \\
0 & 0 & 0 & $n$ \\
\hdashline & 1 & -1
\end{tabular}

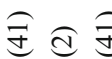

गु

ब્ર

字 $2 \precsim \stackrel{\infty}{=}$

กิ

$\sqrt[3]{a} \sqrt{2}$

층 용

(1)

\%

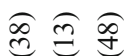

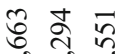

iे

高气

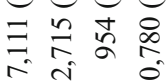

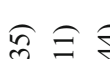

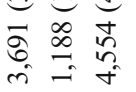

孚老 $\sqrt{2}$

तิ

के ले

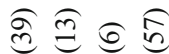

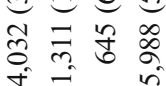

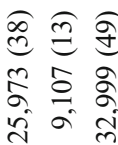

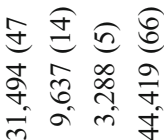

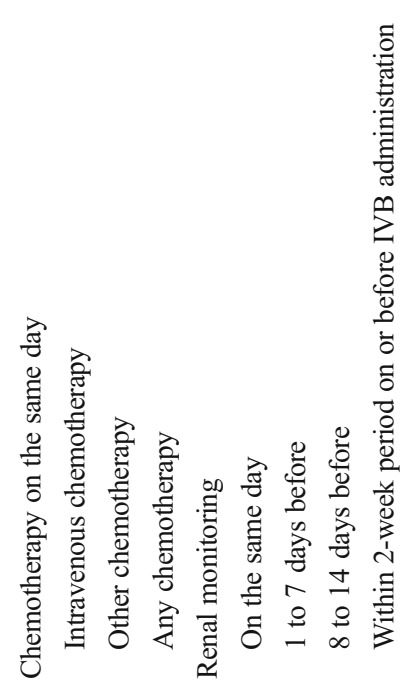

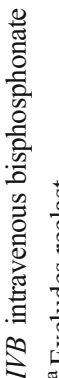


Table 4 Proportional hazard models for receipt of IVB by tumor type

\begin{tabular}{|c|c|c|c|c|c|c|}
\hline \multirow[t]{2}{*}{ Covariate $^{\mathrm{a}}$} & \multicolumn{2}{|l|}{$\begin{array}{l}\text { Breast cancer with } \\
\text { bone metastasis }\end{array}$} & \multicolumn{2}{|l|}{$\begin{array}{l}\text { Lung cancer with } \\
\text { bone metastasis }\end{array}$} & \multicolumn{2}{|c|}{$\begin{array}{l}\text { Prostate cancer with } \\
\text { bone metastasis }\end{array}$} \\
\hline & $\begin{array}{l}\text { Hazard ratio } \\
(95 \% \mathrm{CI})\end{array}$ & $P$ value & $\begin{array}{l}\text { Hazard ratio } \\
(95 \% \mathrm{CI})\end{array}$ & $P$ value & $\begin{array}{l}\text { Hazard ratio } \\
(95 \% \mathrm{CI})\end{array}$ & $P$ value \\
\hline Hypercalcemia (vs. none) ${ }^{\mathrm{b}}$ & $1.86(1.49,2.32)$ & $<0.001$ & $1.95(1.42,2.68)$ & $<0.001$ & $1.47(0.86,2.51)$ & 0.162 \\
\hline \multicolumn{7}{|l|}{$\mathrm{SRE}^{\mathrm{b}}$} \\
\hline Spinal cord compression (vs. none) & $0.85(0.62,1.15)$ & 0.288 & $0.92(0.60,1.42)$ & 0.700 & $1.21(0.72,2.02)$ & 0.469 \\
\hline Pathological fracture (vs. none) & $1.14(1.03,1.25)$ & 0.007 & $1.11(0.96,1.27)$ & 0.159 & $1.14(0.96,1.34)$ & 0.131 \\
\hline Surgery to bone (vs. none) & $1.19(1.05,1.35)$ & 0.007 & $1.21(1.00,1.46)$ & 0.050 & $1.05(0.82,1.35)$ & 0.703 \\
\hline Radiotherapy (vs. none) & $1.34(1.26,1.43)$ & $<0.001$ & $1.06(0.97,1.15)$ & 0.218 & $1.16(1.06,1.28)$ & 0.001 \\
\hline \multicolumn{7}{|l|}{ Index year (vs. 2003) } \\
\hline 2004 & $1.09(0.96,1.25)$ & 0.190 & $1.16(0.96,1.41)$ & 0.128 & $0.89(0.75,1.05)$ & 0.154 \\
\hline 2005 & $1.34(1.18,1.53)$ & $<0.001$ & $1.23(1.02,1.47)$ & 0.030 & $1.04(0.89,1.22)$ & 0.625 \\
\hline 2006 & $1.22(1.08,1.39)$ & 0.002 & $1.33(1.11,1.59)$ & 0.002 & $0.99(0.84,1.17)$ & 0.927 \\
\hline 2007 & $1.29(1.14,1.46)$ & $<0.001$ & $1.25(1.05,1.49)$ & 0.013 & $0.86(0.73,1.01)$ & 0.073 \\
\hline 2008 & $1.32(1.17,1.49)$ & $<0.001$ & $1.24(1.05,1.48)$ & 0.013 & $1.02(0.87,1.19)$ & 0.817 \\
\hline 2009 & $1.38(1.23,1.56)$ & $<0.001$ & $1.25(1.05,1.47)$ & 0.011 & $0.88(0.75,1.02)$ & 0.098 \\
\hline 2010 & $1.25(1.11,1.42)$ & $<0.001$ & $1.24(1.04,1.48)$ & 0.015 & $0.88(0.75,1.03)$ & 0.120 \\
\hline 2011 (through June 30) & $0.87(0.73,1.03)$ & 0.104 & $0.98(0.79,1.23)$ & 0.875 & $0.65(0.51,0.82)$ & $<0.001$ \\
\hline \multicolumn{7}{|l|}{ Age at index date (vs. less than 55 years) } \\
\hline 55 to 64 & $1.00(0.95,1.06)$ & 0.933 & $1.01(0.92,1.10)$ & 0.897 & $1.04(0.88,1.23)$ & 0.676 \\
\hline 65 to 74 & $0.87(0.80,0.94)$ & $<0.001$ & $0.92(0.83,1.02)$ & 0.125 & $1.05(0.89,1.25)$ & 0.548 \\
\hline$\geq 75$ & $0.71(0.65,0.78)$ & $<0.001$ & $0.80(0.71,0.90)$ & $<0.001$ & $0.88(0.75,1.05)$ & 0.153 \\
\hline Male (vs. Female) & - & - & - & - & - & - \\
\hline \multicolumn{7}{|l|}{ Region (vs. south) } \\
\hline North Central & $0.94(0.89,1.00)$ & 0.050 & - & - & $1.01(0.93,1.10)$ & 0.801 \\
\hline West & $0.84(0.78,0.90)$ & $<0.001$ & - & - & $0.78(0.70,0.86)$ & $<0.001$ \\
\hline Northeast & $0.77(0.71,0.83)$ & $<0.001$ & - & - & $0.74(0.66,0.83)$ & $<0.001$ \\
\hline Unknown & $0.64(0.52,0.78)$ & $<0.001$ & - & - & $0.90(0.70,1.15)$ & 0.399 \\
\hline \multicolumn{7}{|l|}{ Plan type (vs. PPO) } \\
\hline Comprehensive & $0.92(0.85,0.99)$ & 0.029 & $0.84(0.77,0.92)$ & $<0.001$ & $0.86(0.79,0.94)$ & $<0.001$ \\
\hline $\mathrm{HMO}$ & $0.76(0.70,0.82)$ & $<0.001$ & $0.73(0.66,0.82)$ & $<0.001$ & $0.68(0.60,0.77)$ & $<0.001$ \\
\hline Other & $0.92(0.86,0.99)$ & 0.025 & $0.87(0.79,0.97)$ & 0.012 & $0.89(0.79,1.02)$ & 0.091 \\
\hline \multicolumn{7}{|c|}{ Charlson index assessed during pre-index period (vs. 2or less) } \\
\hline 3 & - & - & - & - & $1.05(0.97,1.15)$ & 0.242 \\
\hline 4 to 8 & - & - & - & - & $0.83(0.76,0.92)$ & $<0.001$ \\
\hline $9+$ & - & - & - & - & $0.79(0.68,0.93)$ & 0.004 \\
\hline \multicolumn{7}{|c|}{ Additional sites of metastases during pre-index period } \\
\hline Lymph nodes (vs. none) & - & - & - & - & - & - \\
\hline Respiratory sites (vs. none) & $0.89(0.82,0.97)$ & 0.005 & $1.22(1.08,1.37)$ & 0.001 & - & - \\
\hline Liver (vs. none) & - & - & - & - & - & - \\
\hline Central nervous system (vs. none) & $0.68(0.60,0.76)$ & $<0.001$ & $0.72(0.65,0.80)$ & $<0.001$ & - & - \\
\hline Other sites (vs. none) & $0.90(0.83,0.98)$ & 0.011 & $0.83(0.73,0.94)$ & 0.003 & - & - \\
\hline \multicolumn{7}{|l|}{ Visits to specialist during pre-index period } \\
\hline Hematologist (vs. none) & $1.05(0.99,1.12)$ & 0.074 & - & - & $1.30(1.17,1.45)$ & $<0.001$ \\
\hline Oncologist (vs. none) & - & - & - & - & $1.12(1.02,1.23)$ & 0.016 \\
\hline Urologist (vs. none) & - & - & - & - & $0.93(0.87,1.00)$ & 0.065 \\
\hline
\end{tabular}


Table 4 (continued)

\begin{tabular}{|c|c|c|c|c|c|c|}
\hline \multirow[t]{2}{*}{ Covariate $^{\mathrm{a}}$} & \multicolumn{2}{|l|}{$\begin{array}{l}\text { Breast cancer with } \\
\text { bone metastasis }\end{array}$} & \multicolumn{2}{|l|}{$\begin{array}{l}\text { Lung cancer with } \\
\text { bone metastasis }\end{array}$} & \multicolumn{2}{|c|}{$\begin{array}{l}\text { Prostate cancer with } \\
\text { bone metastasis }\end{array}$} \\
\hline & $\begin{array}{l}\text { Hazard ratio } \\
(95 \% \mathrm{CI})\end{array}$ & $P$ value & $\begin{array}{l}\text { Hazard ratio } \\
(95 \% \mathrm{CI})\end{array}$ & $P$ value & $\begin{array}{l}\text { Hazard ratio } \\
(95 \% \mathrm{CI})\end{array}$ & $P$ value \\
\hline \multicolumn{7}{|l|}{ Healthcare utilization during pre-index period } \\
\hline Hospitalization (vs. none) & $0.87(0.81,0.93)$ & $<0.001$ & $0.85(0.79,0.91)$ & $<0.001$ & $0.87(0.79,0.97)$ & 0.011 \\
\hline Oral bisphosphonate (vs. none) & - & - & $1.17(1.00,1.37)$ & 0.054 & - & - \\
\hline \multicolumn{7}{|c|}{ Number of physician office or hospital outpatient visits (vs. 10 or less) } \\
\hline 11 to 15 & $0.99(0.93,1.06)$ & 0.858 & $0.97(0.88,1.08)$ & 0.600 & - & - \\
\hline 16 to 25 & $0.95(0.89,1.01)$ & 0.110 & $0.89(0.80,0.98)$ & 0.021 & - & - \\
\hline $25+$ & $0.76(0.71,0.83)$ & $<0.001$ & $0.73(0.66,0.81)$ & $<0.001$ & - & - \\
\hline \multicolumn{7}{|l|}{ Receipt of medications and therapies ${ }^{\mathrm{b}}$} \\
\hline Long-acting opioid (vs. none) & - & - & - & - & - & - \\
\hline Short-acting opioid (vs. none) & $1.06(1.01,1.12)$ & 0.030 & - & - & - & - \\
\hline Chemotherapy (vs. none) & $1.08(1.02,1.16)$ & 0.011 & $1.46(1.34,1.58)$ & $<0.001$ & $1.23(1.11,1.36)$ & $<0.001$ \\
\hline Systemic corticosteroid (vs. none) & $1.11(1.05,1.17)$ & $<0.001$ & $1.46(1.35,1.59)$ & $<0.001$ & $1.16(1.08,1.25)$ & $<0.001$ \\
\hline Targeted therapy (vs. none) & $1.34(1.23,1.45)$ & $<0.001$ & $1.16(1.06,1.28)$ & 0.002 & $1.58(0.97,2.57)$ & 0.064 \\
\hline \multicolumn{7}{|l|}{ Hormonal therapy } \\
\hline LHRH agonist (vs. none) & $1.58(1.35,1.83)$ & $<0.001$ & - & - & $1.58(1.42,1.75)$ & $<0.001$ \\
\hline LHRH antagonist (vs. none) & - & - & - & - & - & - \\
\hline Anti-androgen (vs. none) & - & - & $3.85(1.39,10.62)$ & 0.009 & $1.36(1.27,1.46)$ & $<0.001$ \\
\hline Orchiectomy (vs. none) & - & - & - & - & $1.94(1.53,2.48)$ & $<0.001$ \\
\hline Aromatase inhibitor (vs. none) & $1.20(1.14,1.27)$ & $<0.001$ & - & - & - & - \\
\hline Estrogen receptor downregulators (vs. none) & $1.36(1.22,1.52)$ & $<0.001$ & - & - & - & - \\
\hline Selective estrogen receptor modulators (vs. none) & $1.13(1.05,1.21)$ & 0.001 & - & - & - & - \\
\hline Other hormonal therapy (vs. none) & - & - & - & - & - & - \\
\hline
\end{tabular}

SRE skeletal-related event; $P P O$ preferred provider organization; HMO health maintenance organization; $L H R H$ luteinizing hormone-releasing hormone; $C I$ confidence interval

${ }^{a}$ Covariates were selected into the model based on $p \leq 0.20$ and dropped when $p \geq 0.10$. SREs and hypercalcemia were forced into the model

${ }^{\mathrm{b}}$ Time-dependent covariates

in the prostate cancer cohort. Receipt of short-acting opioids, chemotherapy, systemic corticosteroids, targeted therapies, and various hormonal therapies were all associated with higher use of IVBs in all cancer types.

\section{Discussion}

This was a retrospective, observational study using health insurance claims data to document IVBs practice patterns in patients with bone metastases secondary to breast, prostate, or lung cancer. To the best of our knowledge, this study is the first to report such results. The use of IVBs was greatest among breast cancer patients (59\%), followed by prostate (43\%) and lung (33\%) cancer patients. For most of the patients who received IVBs, treatment was initiated within
12 months from the date of diagnosis of bone metastasis. The reason for the relatively high frequency of utilization of IVBs among breast cancer patients relative to prostate and especially lung cancer patients is unknown but may relate to the perceived relative prognosis of patients. Because breast cancer patients having the longest expected survival, clinicians may reason that these patients are most likely to benefit from IVB treatment.

Interruption of IVB treatment defined as a gap in administration of 60 days or more was relatively frequent. At 12 months after IVB therapy initiation, the cumulative incidence of interruption was $29 \%$ in breast cancer patients, $31 \%$ in prostate cancer patients, and $16 \%$ in lung cancer patients. At 12 months after IVB initiation, it was estimated that $46 \%$ of breast cancer patients, $56 \%$ of prostate cancer patients, and $83 \%$ of lung cancer patients had discontinued IVB therapy. 
The high cumulative incidence of discontinuation and lower frequency of interruption among lung cancer patients likely reflects their relatively poor prognosis and survival.

IVB was administered concurrently with IV chemotherapy in only 26 to $54 \%$ of IVB administrations. This suggests that the administration of IVBs may be associated with substantial incremental costs associated with the administration of such therapy. Also, renal monitoring prior to IVB administration was not necessarily conducted as recommended in FDA approved labeling [14], as only 42 to $65 \%$ of IVB administrations were accompanied by renal monitoring on the same day or within a 2-week period before IVB administration. The percent of patients receiving renal monitoring on the day of IVB administration was least for prostate cancer patients. These patients were also least likely to receive IV chemotherapy on the day of IVB administration. Further research is required to understand the reasons and outcomes associated with poor compliance with recommended renal monitoring for patients receiving IVBs.

Not surprisingly, patients with SREs were more likely to receive IVBs. Use of IVBs declined with age. Similar results with respect to age were reported by Giordano et al. in a study conducted among breast cancer patients with age 65 or older [15]. Index year of 2011 was associated with lower IVB utilization, although this association was not statistically significant. This result could be due to incomplete data for year 2011 as the study period ended on June 30, 2011.

Some inherent limitations in health insurance claim data generally and the Truven databases in particular should be noted. Health insurance claims data contain information on diagnosis and procedure codes from health insurance claims. In the clinical setting, some conditions or procedures may not be coded and different providers may use different codes for the same diagnosis or procedure. Codes used in this study for the identification of breast, prostate, and lung cancer, bone metastases, and comorbid conditions are consistent with those used in prior published studies and the previous study of the utilization of IV bisphosphonates [6]. However, the sensitivity and specificity of these codes measured against a "gold standard" of a clinically rich dataset such as a trial dataset or electronic medical record have not been assessed.

The particular database used in this study is based on a large convenience sample. Because the sample is not random, it may contain biases or fail to generalize well to other populations. Specifically, the data come from mostly large employers. As a consequence, persons employed in medium and small firms are not well represented. Also, the database does not include Medicaid patients so that children and lower income individuals are not well represented. While Truven databases are geographically diverse, they are not geographically representative of the
United States population. Although the databases include information on lab tests received, they do not include lab results, so it is not possible to characterize patients in terms of clinical metrics such as prostate specific antigen, lactose dehydrogenase, and tumor markers nor is information on cancer staging available. While the claims' histories are largely complete for patients in the commercial database, there may be gaps in the claims history of Medicare patients when Medicare either pays $100 \%$ (and hence there is no coordination of benefit with the retiree benefit plan) or denies payment altogether for a claim. The former situation may occur under part A (i.e., for hospital claims) when patients hit their deductible typically when they are admitted multiple times within a defined benefit period (typically 60 days). So for the sickest patients, some hospital claims may be missing. This likely had little effect on our estimates of utilization of IVBs, as these are typically administered in the outpatient setting. Also, mortality information was unavailable and disenrollment information was used as a proxy for death. Although patients who have metastatic cancer are presumably unlikely to enroll from their health plans, we were not able to validate use of disenrollment as a proxy for death in this population. Lastly, although denosumab was approved for use in prevention of SREs in patients with bone metastases of solid tumors in November 2010, the frequency of denosumab claims was sparse in our databases and therefore analyses of denosumab utilization were not conducted. Further research should focus on the effects of the addition of denosumab to the armamentarium of treatments for bone metastases on the extent of treatment and outcomes for patients who are candidates for such therapy.

In conclusion, IVBs are used more frequently in patients with bone metastases secondary to breast cancer than prostate or lung cancer with many patients interrupting or discontinuing IVB therapy within 12 months of initiation. Previous claims data analyses have shown that nonpersistent zoledronic acid use was associated with higher monthly rates of skeletal complications [16]. These results suggest that there are gaps in treatment of patients with bone metastases and that outcomes for these patients might be improved by expanding utilization of therapies to prevent SREs.

Acknowledgments The study was funded by Amgen. Amy ForemanWykert, Ph.D (Amgen Inc.) provided formatting assistance for this manuscript.

Conflict of interest The manuscript was funded by Amgen. May Hagiwara, Ph.D. and Thomas E. Delea, MSIA are employees of Policy Analysis Inc. (PAI) and have received research funding from Amgen Inc. Ze Cong, Ph.D. and Karen Chung, PharmD, MS are employees of and own stock options in Amgen, Inc. The authors had full control of the primary data and will allow the journal to review the data if requested. 


\section{Appendix}

Table 5 ICD-9-CM diagnosis codes used in the analysis

\begin{tabular}{lll}
\hline Cancer site & Codes for primary malignancy codes & Secondary malignancy codes \\
\hline Lung & $162 . x x, 163 . x x, 164.0 x, 164.2 x, 164.3 x$, and 165.xx & $197.0 x, 197.1 x, 197.2 x$, and 197.3x \\
Gastrointestinal & $150 . x x, 151 . x x, 152 . x x, 153 . x x, 154 . x x, 159.0 x$, and 159.1x & $197.4 x, 197.5 x, 197.6 x$, and 197.8x \\
Liver & $155 . x x$ & $197.7 x$ \\
Breast & $174 . x x$ and 175.xx & 198.81 \\
Kidney and urinary tract & $188 . x x$ and 189.xx & $198.0 x$ and 198.1x \\
Brain & $191 . x x$ and 192.xx & $198.3 x$ and 198.4 \\
Adrenal grand & $194 . x x$ & $198.7 x$ \\
Reproductive organs & $180 . x x, 182 . x x, 183 . x x$, and 184.xx & 198.82 and 198.6x \\
\hline
\end{tabular}

Primary cancers were identified based on ICD-9-CM diagnosis codes 140.xx-195.xx, 200.xx-208.xx, except for 171.xx (malignant neoplasm of connective and other soft tissue), 173.xx (other malignant neoplasm of skin), and 195.xx (malignant neoplasm of other and ill-defined sites)

\section{References}

1. Coleman RE (1997) Skeletal complications of malignancy. Cancer 80:1588-1594

2. Yong M, Jensen AO, Jacobsen JB, Norgaard M, Fryzek JP, Sorensen HT (2011) Survival in breast cancer patients with bone metastases and skeletal-related events: a population-based cohort study in Denmark (1999-2007). Breast Cancer Res Treat 129:495-503

3. Norgaard M, Jensen AO, Jacobsen JB, Cetin K, Fryzek JP, Sorensen HT (2010) Skeletal related events, bone metastasis and survival of prostate cancer: a population based cohort study in Denmark (1999 to 2007). J Urol 184:162-167

4. Berenson JR, Lichtenstein A, Porter L, Dimopoulos MA, Bordoni R, George S, Lipton A, Keller A, Ballester O, Kovacs M, Blacklock H, Bell R, Simeone JF, Reitsma DJ, Heffernan M, Seaman J, Knight RD (1998) Long-term pamidronate treatment of advanced multiple myeloma patients reduces skeletal events. Myeloma Aredia Study Group J Clin Oncol 16:593-602

5. Berenson JR, Lichtenstein A, Porter L, Dimopoulos MA, Bordoni R, George S, Lipton A, Keller A, Ballester O, Kovacs MJ, Blacklock HA, Bell R, Simeone J, Reitsma DJ, Heffernan M, Seaman J, Knight RD (1996) Efficacy of pamidronate in reducing skeletal events in patients with advanced multiple myeloma. Myeloma Aredia Study Group N Engl J Med 334:488-493

6. Saad F, Gleason DM, Murray R, Tchekmedyian S, Venner P, Lacombe L, Chin JL, Vinholes JJ, Goas JA, Chen B (2002) A randomized, placebo-controlled trial of zoledronic acid in patients with hormone-refractory metastatic prostate carcinoma. J Natl Cancer Inst 94:1458-1468

7. Fizazi K, Carducci M, Smith M, Damiao R, Brown J, Karsh L, Milecki P, Shore N, Rader M, Wang H, Jiang Q, Tadros S, Dansey R, Goessl C (2011) Denosumab versus zoledronic acid for treatment of bone metastases in men with castration-resistant prostate cancer: a randomised, double-blind study. Lancet 377:813-822

8. Deyo RA, Cherkin DC, Ciol MA (1992) Adapting a clinical comorbidity index for use with ICD-9-CM administrative databases. J Clin Epidemiol 45:613-619

9. Hagiwara M, Delea TE, Saville MW, Chung K (2013) Healthcare utilization and costs associated with skeletal-related events in prostate cancer patients with bone metastases. Prostate Cancer Prostatic Dis 16:23-27

10. Satagopan JM, Ben-Porat L, Berwick M, Robson M, Kutler D, Auerbach AD (2004) A note on competing risks in survival data analysis. Br J Cancer 91:1229-1235

11. Bergstralh E (2008) Locally Written SAS Macros. Division of Biomedical Statistics and Informatics. Mayo Clinic http:// mayoresearch.mayo.edu/mayo/research/biostat/sasmacros.cfm. Accessed 27 March 2013

12. Vera-Llonch M, Weycker D, Glass A, Gao S, Borker R, Barber B, Oster $\mathrm{G}$ (2011) Healthcare costs in patients with metastatic lung cancer receiving chemotherapy BMC health services research 11: 305

13. Vera-Llonch M, Weycker D, Glass A, Gao S, Borker R, Qin A, Oster G (2011) Healthcare costs in women with metastatic breast cancer receiving chemotherapy as their principal treatment modality. BMC cancer 11:250

14. Novartis Pharmaceuticals Corporation (2012) Zometa ${ }^{\circledR}$ (zoledronic acid) Prescribing Information. November 2012 http://www.pharma. us.novartis.com/product/pi/pdf/Zometa.pdf. Accessed 21 March 2013

15. Giordano SH, Fang S, Duan Z, Kuo YF, Hortobagyi GN, Goodwin JS (2008) Use of intravenous bisphosphonates in older women with breast cancer. The oncologist 13:494-502

16. Hatoum HT, Lin SJ, Smith MR, Barghout V, Lipton A (2008) Zoledronic acid and skeletal complications in patients with solid tumors and bone metastases: analysis of a national medical claims database. Cancer 113:1438-1445 